УДК $005.334(043)$

ГРНТИ 06.81.12

\title{
Гармонизация промышленной и торговой политики промышленного предприятия
}

\author{
К.С. Бармашов, к.э.н. \\ e-mail:k.barmashov@ru.faberlic.com
}

\begin{abstract}
Аннотация
Предмет/mема. В статье рассматриваются вопросы гармонизации промышленной и торговой политики промышленного предприятия, позволяющие повысить эффективность деятельности предприятия. Цели/задачи. Целью работы является анализ понятия гармонии в экономических отношениях и разработка методологических основ гармонизации промышленной и торговой политики промышленного предприятия. Методология. На основе анализа понятия гармонии в экономических отношениях уточнено понятие гармонизации промышленной и торговой политики предприятия с учетом обеспечения экономической безопасности; определены подходы к гарантированию защиты интересов предприятия. По своему содержанию гармонизация промышленной и торговой политики предприятия - это, с одной стороны стратегический план производства и продаж, а с другой стороны, рабочий инструмент для достижения стратегического плана, который имеет количественную реальную меру и жесткую логику, проявляющиеся в соответствующих моделях построения гармоничных отношений между производством и продажами на предприятии. Результаты. Сделан вывод о важности гармонизации промышленной и торговой политики промышленного предприятия, предложена концептуальная модель гармонизации промышленной и торговой политики промышленного предприятия с учетом этапов полного цикла промышленной и торговой политики предприятия. Bbыводы/значимость. Показано, что исследование вопросов гармонии в экономике раскрывает сущность антагонистических противоречий во внешней и внутренней средах деятельности участников экономических отношений, а по своему содержанию гармонизация промышленной и торговой политики предприятия является рабочим инструментом стратегического планирования. Применение. Рассмотренные в статье методологические положения по гармонизации промышленной и торговой политики предприятия могут быть использованы при совершенствовании стратегического и тактического планирования деятельности промышленных предприятий.
\end{abstract}

Ключевые слова: гармония, гармонизащия, промышленное предприятие, промышленная политика, торговая политика, экономическая безопасность

DOI: https://doi.org/10.33051/2500-2325-2019-1-27-36

Вопросы гармонии в экономике или гармонии в экономических отношениях стали рассматриваться с середины XIX века и первым трудом в данной сфере была работа «Экономические гармонии» Ф. Бастиа [3]. Ключевая мысль Ф. Бастиа связана с тем фактом, что возможности участников экономических отношении в значительной степени превосходят их нужды (так называемый эффект синергии), в силу этого экономические отношения в полной мере свободны от существующих антагонистических противоречий во внешней и внутренней средах экономической деятельности. В известном словаре Владимира Даля гармония рассматривается как соответствие, соразмерность, согласность, соразмерные отношения частей целого [7].

В начале 20-го века элементы теории гармонии в экономике рассматривались в работах К. Адамецки [1] и А.А. Богданова [5] (Малиновского). При этом ключевой особенностью гармонизации экономических отношений оба автора считали наличие цели (системы согласованных целей и показателей). В СССР в середине XX века доминирует закон обеспечения пропорционального планомерного развития экономики, это так называемый период осуществления «насильственной гармонизации» участников экономических отношений. В социальных и экономических отношениях данный период проявился как период жесткого регулирования производственных и торговых действий участников экономических отношений и использованием экономико-математических моделей [12]. В указанный период обеспечение гармонии в экономике связано с разработкой межрегиональных и межотраслевых моделей построения народного хозяйства (А.Г. Аганбегян, А.Г. Гранберг), различных моделей прогнозирования экономических отношений, текущего (оперативного) перспективного планирования деятельности участ- 
ников экономических отношений (Н.П. Федоренко, С.С. Шаталин, Б.Б. Розин, В.А. Волконский). В это же время в зарубежных странах формируется так называемое гуманистическое направление применительно к обеспечению гармонии в экономике [13], которое так или иначе рассматривает проблемы гармонии в экономике.

В современных экономических публикациях следует выделить работы А.С. Муратова [16], Д.С. Петросяна [19], М. Эллмана [20], А.И. Клевина [13]. В таблице 1 приведены основные определения понятия гармонии в экономике.

Таблица 1

Основные определения понятия гармонии в экономике

\begin{tabular}{|c|c|}
\hline Автор & Определение \\
\hline Ф. Бастиа & $\begin{array}{l}\text { Ситуация, когда возможности участников экономических отношений в } \\
\text { значительной степени превосходят их нужды (так называемый эффект } \\
\text { синергии), в силу этого экономические отношения в полной мере сво- } \\
\text { бодны от существующих антагонистических противоречий во внеш- } \\
\text { ней и внутренней средах деятельности участников экономических от- } \\
\text { ношений. }\end{array}$ \\
\hline Л.В. Канторович & $\begin{array}{l}\text { Состояние участника экономических отношений, обусловленное раз- } \\
\text { работкой межрегиональных и межотраслевых моделей построения } \\
\text { народного хозяйства, различных моделей прогнозирования эконом- } \\
\text { ческих отношений, текущего (оперативного) перспективного планиро- } \\
\text { вания деятельности участников экономических отношений (осуществ- } \\
\text { ление насильственной гармонизации экономических отношений). }\end{array}$ \\
\hline А. Маслоу & $\begin{array}{l}\text { Позитивное состояние участника экономических отношений, обуслов- } \\
\text { ленное развитием человеческих ресурсов, что позволяет расширять } \\
\text { возможности участника и балансировать их с нарастающими потреб- } \\
\text { ностями и установленными целями развития производства. }\end{array}$ \\
\hline $\begin{array}{l}\text { А.И. Клевин, } \\
\text { Н.К. Моисеева, } \\
\text { М. Эллман }\end{array}$ & $\begin{array}{l}\text { Позитивное состояние участника экономических отношений, обуслов- } \\
\text { ленное рядом радикальных изменений в модели производственной и } \\
\text { торговой деятельности, в рамках которой на смену иерархиям пришли } \\
\text { сети, а модель функциональной специализации уступила место модели } \\
\text { горизонтальной интеграции, интеллектуальному сотрудничеству } \\
\text { участников экономических отношений, при этом интеллектуальные } \\
\text { активы стали более важными в сравнении с финансовыми и матери- } \\
\text { альными активами участников. }\end{array}$ \\
\hline
\end{tabular}

С учетом данных определений считаем необходимым увязать трактовку понятия гармонии в экономических отношениях с установлением идеального динамичного и/или статичного состояния социально - экономической системы, которое характеризуется пропорциональностью процессов на этапах воспроизводственного цикла (производство, распределение, обмен, потребление), а также упорядоченностью данных процессов, выбранной рациональной моделью специализации системы, максимальной согласованностью и сбалансированностью этих процессов, их соответствием требованиям внешней среды и друг другу по критерию единства социальной, экономической и экологической составляющих деятельности, выраженных соответствующими целевыми установками (системой ключевых показателей) по использованию интеллектуальных и материальных ресурсов системы. Ниже рассмотрим понятие гармонизации промышленной и торговой политики промышленного предприятия.

Фактически, понятие «гармонии в экономике» - субъективное и идеализированное. При этом, в современных социально-экономических условиях очень часто, гармонизация предприятия, его действий, системы интересов обеспечивает расширение условий для совместимости элементов, всей системы развития производственной и торговой деятельности предприятия в целом. При этом гармонизация будет первичной в отношении «качества», «результативности» и «эффективности» мероприятий промышленной и торговой политики предприятия.

Отсюда «нахождение гармонии», «гармонизация» выступают как причина, а качество, эффективность и результативность как следствия, которые характеризуют уровень гармонизации производственных и торговых процессов на предприятии. Важно отметить, что специфиче- 
ским объектом для гармонизации промышленной и торговой политики будут выступать противоречия в производственных и торговых процессах на предприятии и могут быть представлены как важное и необходимое условие их согласования, а к самим производственным и торговым процессам - как мера, как критериальная база (например, степень автономности и зависимости производственных и торговых процессов). Фактически, результатом гармонизации свойств производственных и торговых процессов будет выступать качество гармонизации самих производственных и торговых процессов - эффективность, гармонизации целей промышленной и торговой политики - результативность производства и продаж продукции предприятия.

Гармонизация промышленной и торговой политики - это инструмент для достижения стратегических и тактических планов предприятия; имеет количественную интерпретацию с учетом экономической безопасности всех важнейших интересов предприятия применительно к внутренним и внешним угрозам, который формируется руководством и работниками предприятия посредством осуществления комплекса мероприятий экономического, организационного, правового, социально-психологического и инженерно-технического направлений, затрагивающих, в том числе, и вопросы организации производственной и торговой деятельности предприятия.

Экономическая безопасность на предприятии обеспечивается преимущественно действенностью организационных, материальных, нормативных гарантий в отношении установления, предупреждения (локализации) и пресечения возможных посягательств применительно к порядку управления, к законным правам предприятия, к его имущественным активам, интеллектуальной собственности, благоприятной финансовой и коммерческой конъюнктуре, к устойчивости производственных и торговых процессов на предприятии.

Организационные гарантии создаются посредством разработки и поддержания высокого уровня работоспособности структуры управления процессами и устранения угроз для деятельности предприятия, посредством применения механизма по стимулированию оптимального функционирования системы управления, соответствующей подготовки работников, принятия комплекса мер по консолидацию действий работников для обеспечения экономической безопасности.

В свою очередь, материальные гарантии создаются посредством выделения, рационального применения технических, интеллектуальных, финансовых, кадровых, информационных и прочих ресурсов предприятия, которые обеспечивают своевременное установление, ослабление всех возможных источников угроз, а также предотвращение, локализацию возможных ущербов, создание и расширение спектра благоприятных условий и возможностей для ведения производственной и торговой деятельности предприятия.

Наконец, нормативные гарантии связаны с правовым обеспечением производственной и торговой деятельности предприятия, с формированием на данном базисе соответствующих эффективных юридических отношений с партнерами, установление, защиту правомерности поведения работников и подразделений предприятия при обеспечении безопасности, реализацию комплекса мер административного и государственного принуждения, применение системы санкций в отношении физических и юридических лиц, которые посягали на интересы предприятия при ведении им производственной и торговой деятельности. Нормы права будут определять содержание режима экономической безопасности, что при сочетании с комплексом мер по установлению, поддержанию указанного режима обеспечит требуемый правовой базис всех действий системы безопасности на предприятии.

Автором выделены следующие подходы к обеспечению экономической безопасности интересов предприятия:

- профилактическая деятельность, которая включает разработку, реализацию ряда управленческих мероприятий, которые носят предупредительный характер, направлены на предотвращение и уменьшение ущербов для экономической безопасности подразделений предприятия, работников и членов семей работников. Главные направления данной деятельности в рамках обеспечения экономической безопасности - это комплекс мер, которые принимаются при организации работы с персоналом, ведении информационной деятельности, обеспечении требуемой безопасности имущества, помещений, зданий, сооружений;

- реагирующая деятельность, связанная с реализацией ряда мер, которые направлены на установление нарушений режима экономической безопасности.

Необходимо понимать, что производственная и торговая деятельность современного 
промышленного предприятия предполагает решение широкого спектра организационных вопросов, правовых и экономических проблем, учет большого числа технических и кадровых аспектов. Особенно сложно эффективно управлять производственной и торговой деятельностью крупного промышленного предприятия, которое имеет широкий спектр деловых связей и большое число контрагентов: клиентов, поставщиков, кредиторов. Именно в рамках внешних и внутренних производственных и торговых связей предприятия возникают и реализуются угрозы для экономической безопасности предприятия. Здесь, для обеспечения требуемой степени защиты предприятия от данных угроз возникает важность гармонизации промышленной и торговой политик предприятия. Так как производственная и торговая деятельности как объекты защиты очень сложны, имея значительное число параметров, в данном случае обеспечение требуемого уровня экономической безопасности следует рассматривать в комплексе с мероприятиями по гармонизации промышленной и торговой политик предприятия.

Все это определило тот факт, что в научной литературе есть ряд определений понятия гармонизации промышленной и торговой политики предприятия, в том числе, и с учетом специфики обеспечения экономической безопасности. Например, под гармонизацией промышленной, торговой политик на предприятии с учетом обеспечения экономической безопасности предлагается понимать управляемую деятельность, которая позволяет повысить уровень социально-экономической эффективности, достичь необходимого консенсуса между разнонаправленными экономическими интересами различных субъектов внешней и внутренней среды, пропорционально согласовать разные направления производственной и торговой деятельности предприятия на базе координирующего центра - подразделения стратегического маркетинга, [9]. С данным пониманием термина согласуется определение, данное Т.А. Жарковой, а именно: гармонизация это « ...комплексным образом согласованная и упорядоченная совокупность экономических процессов и элементов системы управления, образующая соразмерное соотношение и взаимовлияние промышленной и торговой деятельности ..» [8, с. 11].

В работе В.Н. Батовой указывается, что проблему гармонизации мероприятий промышленной и торговой политики на предприятии следует считать важнейшей научной задачей стратегического менеджмента предприятия, так как правомерное и рациональное решение указанной проблемы обладает большим хозяйственным значением. В рамках гармонизации на предприятии будет устанавливаться баланс значительного числа микроэкономических и макроэкономических факторов, которые определяют экономическую безопасность, возможности устойчивого развития, оптимальность рыночной стратегии предприятия, экономическую эффективность его проектов, уровень социальной ориентации производственной и торговой деятельности предприятия. Поэтому В.Н. Батова предлагает под гармонизацией понимать формирование эффективной и согласованной системы по производству и реализации продукции, что в перспективе позволит создавать и расширять спектр условий для более эффективного и рационального применения резервов предприятия, выступает базисом для динамического и устойчивого развития предприятия, отраслевых и региональных экономик, функционирования национальной экономики в целом [4].

В статье Ю.А. Клейменовой под процессом гармонизации предлагается понимать деятельность по балансированию экономических интересов предприятия, отдельных микроэкономических агентов, государства по поводу производства, реализации различных видов продукции, работ, услуг, что обеспечивает и производство продукции высокого уровня конкурентоспособности, и реализацию данной продукции на внутренних и мировых товарных рынках по критерию нахождения оптимальных условий для использования материальных и интеллектуальных ресурсов промышленного предприятия [14]. В свою очередь, А.Н. Ахрамеев утверждает, что суть процессов гармонизации связана с выражением системы экономических отношений, рыночных механизмов построения взаимодействий субъектов внешнего и внутреннего окружения предприятия по критерию достижения рациональной и высокой сбалансированности процессов производства и торговли продукцией предприятия. Специфической особенностью определения А.Н. Ахрамеева следует считать тот факт, что в рамках гармонизации происходит регулирование отношений между субъектами, формирующими и реализующими промышленную и торговую политики предприятия как фактора его устойчивого роста посредством мониторинга и стратегического контроля уровня экономической безопасности предприятия. В данном определении стратегическим инструментарием гармонизации реализуется важная цель - социальная и экономическая 
эффективность организации производственной и торговой деятельности предприятия, где функции скидок и расходов стремятся к своему минимуму, при этом функции доходов и уровня социальной защищённости и ответственности (предприятия, его работников, государства) - к максимуму [2].

Наконец, Е.Г. Явич предлагает под мероприятиями гармонизации понимать деятельность, которая направлена на взаимное и разумное согласование объемов промышленного производства, ассортимента продукции предприятия со всеми текущими потребностями локального, национального и мирового рынков. Здесь, обеспечение требуемого уровня сбалансированности между производственными возможностями предприятия и уровнем рыночного платежеспособного спроса позволяет достичь максимальных показателей эффективности производственной и торговой деятельности и гарантировать устойчивое долгосрочное развитие и функционирование предприятия. При этом бессистемный характер изменения объемов производства, который ориентирован исключительно на текущие размеры потребительского спроса для реализации целей по получению возможной максимальной прибыли предприятия в долгосрочном периоде приведет к изменению характера мероприятий по обеспечению экономической безопасности на предприятии [21].

Таблица 2

Описание этапов полного цикла промышленной и торговой политики предприятия

\begin{tabular}{|c|c|c|c|c|c|c|}
\hline Политика & Диагностика & $\begin{array}{c}\text { Формиро- } \\
\text { вание } \\
\end{array}$ & Реализация & $\begin{array}{c}\text { Регулиро- } \\
\text { вание }\end{array}$ & \begin{tabular}{|c|} 
Гармони- \\
зация
\end{tabular} & Развитие \\
\hline \multicolumn{7}{|l|}{ Принципы } \\
\hline $\begin{array}{l}\text { Промыш- } \\
\text { ленная }\end{array}$ & $\begin{array}{l}\text { объективности } \\
\text { оценки произ- } \\
\text { водственного } \\
\text { потенциала и } \\
\text { ассортимента } \\
\text { производимой } \\
\text { продукции } \\
\end{array}$ & $\begin{array}{l}\text { рациональ- } \\
\text { ности во- } \\
\text { влечения } \\
\text { ресурсной } \\
\text { базы про- } \\
\text { изводства }\end{array}$ & \begin{tabular}{|l} 
адекватности и \\
эффективности \\
использования \\
информацион- \\
ных и кадровых \\
ресурсов в сфере \\
производства \\
\end{tabular} & $\begin{array}{l}\text { эффектив- } \\
\text { ности } \\
\text { управлен- } \\
\text { ческих про- } \\
\text { цессов в } \\
\text { сфере про- } \\
\text { изводства } \\
\end{array}$ & $\begin{array}{l}\text { гармонич- } \\
\text { ности } \\
\text { производ- } \\
\text { ства и по- } \\
\text { требления }\end{array}$ & $\begin{array}{l}\text { инновацион- } \\
\text { ности и эко- } \\
\text { логичности } \\
\text { производ- } \\
\text { ственных } \\
\text { процессов }\end{array}$ \\
\hline Topr & $\begin{array}{l}\text { объективности } \\
\text { оценки торгово- } \\
\text { го потенциала и } \\
\text { ассортимента } \\
\text { реализуемой } \\
\text { продукции }\end{array}$ & \begin{tabular}{|l} 
рациональ- \\
ности во- \\
влечения \\
ресурсной \\
базы тор- \\
говли
\end{tabular} & $\begin{array}{l}\text { адекватности и } \\
\text { эффективности } \\
\text { использования } \\
\text { информацион- } \\
\text { ных и кадровых } \\
\text { ресурсов в сфере } \\
\text { торговли }\end{array}$ & $\begin{array}{l}\text { эффектив- } \\
\text { ности } \\
\text { управлен- } \\
\text { ческих про- } \\
\text { цессов в } \\
\text { сфере тор- } \\
\text { говли }\end{array}$ & $\begin{array}{l}\text { гармонич- } \\
\text { ности } \\
\text { сбытовых } \\
\text { и логисти- } \\
\text { ческих } \\
\text { процессов }\end{array}$ & $\begin{array}{l}\text { инновацион- } \\
\text { ности и эко- } \\
\text { логичности } \\
\text { торговых } \\
\text { процессов }\end{array}$ \\
\hline \multicolumn{7}{|l|}{ Мето } \\
\hline Ш- & $\begin{array}{l}\text { оценки произ- } \\
\text { водственного } \\
\text { потенциала и } \\
\text { ассортимента } \\
\text { производимой } \\
\text { продукции } \\
\end{array}$ & \begin{tabular}{|l} 
вовлечения \\
ресурсной \\
базы в \\
производ- \\
ственные \\
процессы \\
\end{tabular} & $\begin{array}{l}\text { использования } \\
\text { информацион- } \\
\text { ных и кадровых } \\
\text { систем в сфере } \\
\text { производства }\end{array}$ & $\begin{array}{l}\text { организации } \\
\text { управленче- } \\
\text { ских про- } \\
\text { цессов в } \\
\text { сфере про- } \\
\text { изводства } \\
\end{array}$ & $\begin{array}{l}\text { гармони- } \\
\text { зации } \\
\text { производ- } \\
\text { ства и по- } \\
\text { требления }\end{array}$ & $\begin{array}{l}\text { инновацион- } \\
\text { ного и эколо- } \\
\text { гического } \\
\text { менеджмента } \\
\text { в сфере про- } \\
\text { изводства } \\
\end{array}$ \\
\hline Торговая & $\begin{array}{l}\text { оценки торгово- } \\
\text { го потенциала и } \\
\text { ассортимента } \\
\text { реализуемой } \\
\text { продукции }\end{array}$ & $\begin{array}{l}\text { вовлечения } \\
\text { ресурсной } \\
\text { базы в тор- } \\
\text { говые про- } \\
\text { цессы }\end{array}$ & $\begin{array}{l}\text { использования } \\
\text { информацион- } \\
\text { ных и кадровых } \\
\text { систем в сфере } \\
\text { торговли }\end{array}$ & $\begin{array}{l}\text { организа- } \\
\text { ции управ- } \\
\text { ленческих } \\
\text { процессов } \\
\text { в сфере } \\
\text { торговли }\end{array}$ & $\begin{array}{l}\text { гармони- } \\
\text { зации } \\
\text { сбытовых } \\
\text { и логисти- } \\
\text { ческих } \\
\text { процессов }\end{array}$ & $\begin{array}{l}\text { инновацион- } \\
\text { ного и эколо- } \\
\text { гического } \\
\text { менеджмента } \\
\text { в сфере тор- } \\
\text { говли }\end{array}$ \\
\hline
\end{tabular}

Все сказанное выше позволяет сформулировать определение гармонизации промышленной и торговой политики предприятия с учетом экономической безопасности, а именно: «гармонизация промышленной и торговой политики промышленного предприятия в самом общем случае - процесс согласования целей, принципов, методов, критериев и показателей производственных, сбытовых и обеспечивающих их бизнес-процессов на всех этапах жизненного цикла политики, который за счет 
обеспечения экономической безопасности на этих этапах приводит к снижению экономического ущерба от производственной, сбытовой и иной деятельности предприятия и способствует оптимизации его экономического поведения». Описание принципов и методов этапов полного цикла промышленной и торговой политики при их ориентации на обеспечение экономической безопасности предприятия приведено в таблице 2.

Оценка и анализ гармонизации полного жизненного цикла промышленной и торговой политики предприятия с учетом обеспечения их экономической безопасности основываются на трех направлениях.

1. Предлагается количественный показатель степени гармонизации между параметрами: цели, задачи, принципы, методы, критерии и показатели, в рамках одной составляющей промышленной и торговой политики, ориентированный на повышение рентабельности и экономической безопасности предприятия. Оценка степени гармонизации параметров проводится методом парных сравнений. Отметим что составляющими промышленной политики являются производственная, маркетинговая, инновационная, финансовая, ассортиментная, информационная, управленческая, кадровая, экологическая и ресурсная, а торговой политики - сбытовая, маркетинговая, транспортно-логистическая, инновационная, финансовая, ассортиментная, информационная, управленческая, кадровая, экологическая, ресурсная политика.

2. Предлагается количественный показатель степени гармонизации между параметрами в целом составляющих промышленной и торговой политики и ориентированный на повышение рентабельности и экономической безопасности предприятия. Оценка степени гармонизации параметров проводится по модифицированному нами методу парных сравнений.

3. Предлагаются количественные показатели оценки качества выполнения этапов диагностики, формирования, реализации, регулирования, гармонизации и развития промышленной и торговой политики предприятия и их составляющих, ориентированные на повышение рентабельности и экономической безопасности предприятия.

Показатели гармонизации полного жизненного цикла политики с учетом обеспечения их экономической безопасности могут быть выражены следующим образом:

$$
\mathbf{Z}_{\mathbf{p}}(\mathbf{m}) \rightarrow \mathbf{Z}_{\mathbf{p}}(\mathbf{p}) \rightarrow \mathbf{Z}_{\mathrm{t}}(\mathbf{p}) \rightarrow \max \mathrm{S} \rightarrow \max \mathbf{R}
$$

где $\mathbf{Z}_{\mathrm{p}}(\mathrm{m})$ - функция гармонизации $\mathbf{Z}$ по параметрам m одной политики $\mathrm{p}$;

$\mathbf{Z}_{\mathrm{p}}(\mathrm{p})$ - функция гармонизации $\mathbf{Z}$ между политиками $\mathrm{p}$;

$\mathbf{Z}_{\mathrm{t}}(\mathrm{p})$ - функция гармонизации $\mathbf{Z}$ между политиками р по каждому этапу $\mathrm{t}$ - жизненного цикла политики;

$\mathbf{S}$ - экономическая безопасность предприятия (с учетом реализации промышленной или торговой политики);

$\mathrm{R}$ - рентабельность предприятия;

Оценка экономической безопасности $(\mathrm{S})$ находится в обратной зависимости от экономического ущерба или потерь в стоимостном выражении $(\mathbf{Y})$, полученных в реализации угроз и их последствий по результатам реализации промышленной и торговой политики с учетом их гармонизации. Причинами потерь могут быть как показал анализ научной литературы, перепроизводство продукции, ее избыточные запасы, неудовлетворительно организованная транспортировка, неэффективная организация и управление [6].

$S=[0 ; 1]$

$\mathbf{S}=\mathbf{1}-\mathbf{K}$, где $\mathbf{K}-$ коэффициент ущерба по относительной шкале [0;1].

При $\mathbf{K}=\mathbf{0}, \mathbf{S}=1$.

При $\mathbf{K}=1, \mathbf{S}=\mathbf{0}$.

$\mathbf{K}=\mathbf{Y}: \mathbf{Y}^{\mathbf{m a x}}$, где $\mathbf{Y}^{\mathbf{m a x}}$ - максимальное значение показателя $\mathbf{Y}$, характеризующего экономические потери в стоимостном выражении. Экономическая безопасность дифференцированно определяется для каждой составляющей промышленной и торговой политики. Однако на практике отнесение ущерба к той или иной составляющей промышленной или торговой политики представляется трудоемким и слабо формализуемым. Поэтому предлагается оценивать экономическую безопасность предлагается с помощью трех показателей: в целом по промышленной и торговой политике, а также по предприятию. Экономическая безопасность по предприятию определяется в зависимости от суммы ущерба по промышленной и торговой политике. 
Выделяют следующие виды рентабельности предприятия: рентабельность активов; уровень рентабельности продукции; рентабельность продаж; рентабельность основных средств; рентабельность персонала; рентабельность инвестиций в предприятие; рентабельность собственного капитала. В нашем случае используются три показателя:

- рентабельность предприятия. Если оценка рентабельности предприятия будет невысокой, то должны приниматься определенные управленческие меры для улучшения ситуации. Возможно, потребуется корректировка производственных затрат, пересмотр методов руководства или рациональности расхода ресурсов;

- рентабельность основных средств. Рентабельность основных средств характеризует промышленную политику предприятия и показывает эффективность экономической деятельности бизнес-проекта; определяется как процентное отношение чистой прибыли к стоимости основных фондов и напрямую зависит от прибыльности; не должен быть меньше нуля, что означает, что предприятие работает с убытками и нерационально использует свои основные средства;

- рентабельность реализованной продукици. Рассчитывается как процентное отношение чистой прибыли к себестоимости. Полученный коэффициент помогает определить эффективность от реализации произведенной продукции и характеризует торговую политику предприятия.

В заключение отметим, что наше определение понятия гармонизации экономических отношениях обусловлено установлением эталонного динамичного и/или статичного состояния социально - экономической системы, характеризующейся пропорциональностью процессов на этапах восроизводственного цикла (производство, распределение, обмен, потребление), а также упорядоченностью данных процессов, выбранной рациональной моделью специализации системы, максимальной согласованностью и сбалансированностью этих процессов, их соответствию требованиям внешней среды и друг другу по критерию единства социальной, экономической, экологической составляющих деятельности, выраженных соответствующими целевыми установками.

\section{Литература} 1972.

1. Адамецки К. О науке организации. [Текст] / Адамецки К. Пер. с польск.- М.: Экономика,

2. Ахрамеев А.Н. Стратегический контроллинг гармонизации промышленной и торговой политики субъектов малого бизнеса: [Текст] / А.Н. Ахрамеев; автореферат диссертации кандидата экономических наук: 08.00.05. - М.: МГУПП, 2014.

3. Бастиа Ф. Экономические гармонии. [Текст] / Ф. Бастиа. Пер. с фр. - М.: Эксмо, 2007.

4. Батова В.Н. Гармонизация торгово-промышленной политики предприятия с учётом экономической безопасности [Текст] / В.Н. Батова // Гуманитарные, социально-экономические и общественные науки. - 2012.- № 5. - С. 344-347.

5. Богданов А.А. Тектология. Всеобщая организационная наука. [Текст] / А.А. Богданов. М.: Финансы, 2003.

6. Вумек Д.П., Джонс Д.Т. Бережливое производство: Как избавиться от потерь и добиться процветания вашей компании [Текст] /Д.П. Вумек, Д.Т. Джонс. / Пер. с англ. - М.: Альпина Бизнес Букс, 2004.

7. Даль В. Толковый словарь. URL: https:/gufo.me/dict/dal/гармония (Дата обращения 13.03.2018).

8. Жаркова Т.А. Обеспечение гармонизации промышленной и торговой политики на примере автомобильной корпорации: [Текст] / Т.А. Жаркова; автореферат диссертации кандидата экономических наук: 08.00.05. М.: СОПС, 2015.

9. Журавлев А.И. Вопросы гармонизации торговой и промышленной политики [Текст] /А.И. Журавлев //Внешняя торговля. - 2009. - № 4 - 6. - С. 25-32.

10. Зоидов К.Х., Омарова З.К., Лебедева А.В. Интеграция предприятий: теоретические аспекты. В сборнике: Стратегическое планирование и развитие предприятий. Материалы тринадцатого Всероссийского симпозиума. Под ред. Г.Б. Клейнера. 2012. - С. 71-73.

11. Зоидов К.Х., Омарова З.К., Лебедева А. Интеграционное взаимодействие предприятий как фактор повышения конкурентоспособности. В сборнике: Стратегическое планирование и развитие предприятий. Материалы Пятнадцатого Всероссийского симпозиума. Под ред. Г.Б. Клейнера. 2014. - С. 84-87. 
12. Канторович Л.В. Экономика и математика: избранное [Текст] /Л.В. Канторович. СПб: Нестор-История, 2012.

13. Клевин А.И. Организация гармоничного производства (теория и практика). [Текст] /А.И. Клевин, Н.К. Моисеев. - М.: Омега-Л, 2003.

14. Клейменова Ю.А. Гармонизация промышленной и торговой политики как фактор модернизации экономики [Текст] /Ю.А. Клейменова //Вестник ЮРГТУ (НПИ). - 2012. - № 3. - C. 146-149.

15. Маслоу А. Мотивация и личность. [Текст] /А. Маслоу. Пер. с англ. - СПб: Питер, 2008.

16. Муратов А.С. Введение в теорию гармонизации. [Текст] /А.С. Муратов -Новосибирск: Наука, 2008.

17. Омарова 3.К. Управление развитием процессов корпоративной интеграции предприятий в регионе //Региональные проблемы преобразования экономики. - 2010. - № 2(24). - С. 7-11.

18. Омарова 3.К. Механизмы правового регулирования деятельности корпоративных объединений //Региональные проблемы преобразования экономики. - 2012. - № 4 (34). - С. 183-189.

19. Петросян Д.С. Методология формирования механизма государственно-общественного регулирования национальной экономики [Текст] /Д.С. Петросян, О.Б. Скрипник //Аудит и финансовый анализ. - 2016. - № 6. - С. 363-369.

20. Эллман М. О вкладе исследовательских работ по советской экономике в экономическую теорию мейнстрима [Текст] /М. Эллман //Вопросы экономики. - 2010. - № 3. - С. 39-55.

21. Явич Е. Г. Основные направления гармонизации торговой и промышленной политики предприятий в условиях поддержания экономической безопасности [Текст] / Е.Г. Явич // Новое слово в науке: стратегии развития. Материалы II Международной научно-практической конференции (Чебоксары, 22 окт. 2017 г.). В 2 т. Т. 2 /Редколл.: О.Н. Широков [и др.] - Чебоксары: ЦНС «Интерактив плюс», 2017. - С. 167-172.

\title{
Об авторе
}

Бармашов Константин Сергеевич, кандидат экономических наук, директор по инновациям и стратегическому развитию, Акционерное общество «Фаберлик», Москва.

\section{Для цитирования}

Бармашов К.С. Гармонизация промышленной и торговой политики промышленного предприятия //Проблемы рыночной экономики. - 2019. - № 1. - С. 27-36.

DOI: https://doi.org/10.33051/2500-2325-2019-1-27-36

\section{Harmonization of industrial and trade policy of the industrial enterprise}

Konstantin S. Barmashov, Cand. of Sci (Econ). e-mail: k.barmashov@ru.faberlic.com

\begin{abstract}
Subject/topic. In article the questions of harmonization of industrial and trade policy of the industrial enterprise allowing to increase efficiency of activity of the enterprise are considered. Goals/Objectives. The purpose of work is the analysis of a concept of harmony of the economic relations and development of methodological bases of harmonization of industrial and trade policy of the industrial enterprise. Methodology. On the basis of the analysis of a concept of harmony in the economic relations the concept of harmonization of industrial and trade policy of the enterprise taking into account ensuring economic security is specified, approaches to guaranteeing protection of interests of the enterprise are defined. According to the contents and an essence harmonization of industrial and trade policy of the enterprise is, on the one hand, the strategic plan of production and sales, and, on the other hand, the working tool for achievement of the strategic plan which has a quantitative real measure and tough logic which are shown in the corresponding models of creation of the harmonious relations between production and sales at the enterprise. Results. The conclusion is drawn on importance of harmonization of industrial and trade policy of the industrial enterprise, the generalized (conceptual) model of harmonization of industrial and trade policy of the industrial enterprise taking into account stages of a full cycle of industrial and trade policy of the enterprise is offered. Conclusions/significance. It is shown that the research of questions of har-
\end{abstract}


mony in economy opens the existing antagonistic contradictions in external and internal environments of activity of participants of the economic relations, and according to the contents and an essence harmonization of industrial and trade policy of the enterprise is the working tool of strategic planning. Application. The methodological regulations considered in article on harmonization of industrial and trade policy of the industrial enterprise can be used at improvement of strategic and tactical planning of activity of the industrial enterprises.

Keywords: harmony, harmonization, industrial enterprise, industrial policy, trade policy, economic security

\section{References}

1. Adamiecki K. On the science of organization. [Text] / K. Adamiecki. Translated from Polish. - Moscow: Economy, 1972 (In Russian).

2. Akhromeev A.N. Strategic controlling of harmonization of industrial and trade policy of subjects of small business [Text] / A.N. Akhromeev; abstract of dissertation of candidate of economic Sciences: 08.00.05. - Moscow: MGUPP. 2014 (In Russian).

3. Bastia F. Economic harmonies. [Text] / F. Bastia. Translated from French. - M.: Eksmo, 2007 (In Russian).

4. Batova V.N. Harmonization of trade and industrial policy of the enterprise taking into account economic security [Text] / V.N. Batova /Humanities, socio-economic and social sciences. 2012. - № 5. - P. 344-347 (In Russian).

5. Bogdanov A.A. Tectology. General organizational science. [Text] /A.A. Bogdanov. - Moscow: Finance, 2003 (In Russian).

6. Vumc D.P., Jones D.T. Lean manufacturing: How to eliminate losses and to achieve prosperity of your company [Text] / D.P. Womak, D.T. Jones. Translated from English. - Moscow: Alpina Business Books, 2004 (In Russian).

7. Dal V. Explanatory dictionary. URL: https://gufo.me/dict/dal/harmony (Access date: 13.03.2018).

8. Zharkova T.A. Ensuring the harmonization of industrial and trade policy on the example of the automobile Corporation: [Text] /T.A. Zharkova. Abstract of the thesis of candidate of economic Sciences: 08.00.05. Moscow: SOPS, 2015 (In Russian).

9. Zhuravlev A.I. Issues of harmonization of trade and industrial policy [Text] /A.I. Zhuravlev //Foreign trade. - 2009. - № 4-6. - P. 25-32 (In Russian).

10. Kantorovich L.V. Economics and mathematics: selected [Text] / L.V. Kantorovich. - SPb: Nestor-History, 2012 (In Russian).

11. Zoidov K.Kh., Omarova Z.K., Lebedeva A.V. Enterprise Integration: theoretical aspects. In the collection: Strategic planning and development of enterprises. Proceedings of the thirteenth allRussian Symposium. Edited by G.B. Kleiner. 2012. P. 71-73 (In Russian).

12. Zoidov K.H., Omarova Z.K., Lebedeva A.V. Integration interaction of enterprises as a factor of competitiveness increase. In the collection: Strategic planning and development of enterprises. Proceedings of the Fifteenth all-Russian Symposium. Edited by G.B. Kleiner. 2014. P. 84 (In Russian).

13. Klevin A.I. Organization of harmonious production (theory and practice). [Text] /A.I. Klevyn, N.To. Moses. - M.: Omega-L, 2003 (In Russian).

14. Kleimenova $Y$. Harmonization of industrial and trade policies as a factor of modernization of the economy [Text] /Y.A. Kleymenova //Vestnik YURGTU (NPI). - 2012. - № 3. - P. 146-149 (In Russian).

15. Maslow A. Motivation and personality. [Text] /A. Maslow. Translated from English. - St. Petersburg: Peter, 2008 (In Russian).

16. Muratov A.S. Introduction to the theory of harmonization. [Text] / A.S. Muratov Novosibirsk: Nauka, 2008 (In Russian).

17. Omarova Z.K. Management of development of processes of corporate integration of enterprises in the region //Regional problems of economic transformation. - 2010. - № 2 (24). - P. 7 (In Russian).

18. Omarova Z.K. Mechanisms of legal regulation of corporate associations //Regional problems of economic transformation. - 2012. - № 4 (34). - C. 183-189 (In Russian). 
19. Petrosyan D.S. Methodology of formation of the mechanism of state-public regulation of the national economy [Text] /D.S. Petrosyan, O.B. Skripnik //Audit and financial analysis. - 2016. - № 6. P. 363-369 (In Russian).

20. Ellman M. On the contribution of research on the Soviet economy in the economic theory of the mainstream [Text] /M. Ellman //Economic Issues. - 2010. - № 3. - P. 39-55 (In Russian).

21. Yavich E.G. The Main directions of harmonization of trade and industrial policy of enterprises in terms of maintaining economic security [Text] / E.G. Yavich //New word in science: development strategies. Proceedings of the II International scientific-practical conference (Cheboksary, 22 Oct. 2017). In 2 Volums. V. 2 /O.N. Shirokov [et al.] - Cheboksary: CNS "Interactive plus", 2017. - P. 167-172 (In Russian).

\section{About author}

Konstantin S. Barmashov, Candidate of Sci. (Econ.), Director for Innovation and Strategic Development of Faberlic joint-stock company, Moscow.

\section{For citation}

Barmashov K.S. Attraction of Foreign Investments in Oil and Gas Industry of the Russian Federation //Market economy problems. - 2019. - № 1. - P. 27-36 (In Russian).

DOI: https://doi.org/10.33051/2500-2325-2019-1-27-36 